\begin{tabular}{|l|l|}
\hline $\begin{array}{l}\text { Postprint } \\
\text { Version }\end{array}$ & 1.0 \\
\hline \begin{tabular}{l} 
Journal website \\
http://journals.cambridge.org/action/displayAbstract?fromPage=online\&aid=26 \\
\hline Pubmed link
\end{tabular} & $10.1017 /$ S003329179900851X \\
\hline DOI & \\
\hline
\end{tabular}

This is a NIVEL certified Post Print, more info at http://www.nivel.eu

\title{
The general practitioner as the first contacted health professional by patients with psychosocial problems: a European study
}

\author{
WIENKE G.W. BOERMA" AND PETER F.M. VERHAAK
}

From the Netherlands Institute for Primary Health Care (NIVEL), Utrecht, The Netherlands

" Address for correspondence: Mr Wienke G. W. Boerma, NIVEL, PO Box 1568, 3500 BN Utrecht, The Netherlands.

\begin{abstract}
Background. There are considerable differences between and within countries in the involvement of general practitioners (GPs) in psychosocial care. This study aimed to describe the self-perceived role of GPs in 30 European countries as the first contacted professional for patients with psychosocial problems, and to examine the relationship with characteristics of the health care system, practice organization and doctors.

Methods. Data collected in the European Study of GP Task Profiles were analysed in relation to the self-perceived involvement of GPs in psychosocial care. In 30 countries 7233 GPs answered standardized questionnaires in their own languages about seven brief case scenarios. The questions focused on care given as the first health care professional contacted, and were answered in a scored scale (1-4) ranging from `never' to `almost always'. Independent variables examined were both on a national level and on an individual level, including: listed practice population, referral system, employment status of GPs, workload, measures of practice organization, contacts with social workers and urbanization of practice area. Data were analysed using multi-level techniques.

Results. Self-perceived involvement in psychosocial care was much higher in Western than in Eastern Europe and also in countries with a referral system. Cooperation with social workers, rural practice, keeping medical records, presence of an appointment system and high workload were positively associated with this perceived involvement.

Conclusions. In countries with self-employed doctors and a referral system, GPs are in a better position to provide psychosocial care. GPs should be encouraged to cooperate with social workers and to keep medical records of their patient contacts routinely.
\end{abstract}

\section{INTRODUCTION}

General practitioners (GPs), in some countries referred to as family physicians, are often the first professional person contacted when patients experience mental and social problems. This is even more the case if mental or social problems are manifested in somatic symptoms (Regier et al. 1982; Schulberg, 1987;Goldberg\&Huxley, 1992; Kirmayer et al. 1993; Kroenke et al. 
Boerma, W.G.W., Verhaak, P.F.M. The general practitioner as the first contacted health professional by patients with psychosocial problems: a European study. Psychological Medicine: 1999, 29(3), p. 689-696

1994; Üstün \& Sartorius, 1995).

Many patients receiving mental health care are treated solely by GPs (Schurman et al. 1985; Olfson, 1991; Bensing \& Verhaak, 1994; Verhaak, 1995a, $b$ ) and in those countries with well developed systems of primary health care, GPs are most important sources of referral to specialist mental health care (Gater et al. 1991; éiesvold et al. 1998). Goldberg \& Huxley $(1980,1992)$ consider the GP as the most appropriate filter between the general public and specialist psychiatric services.

There are however, large differences between GPs in the way they fulfil this function. Within health care systems there are large individual differences, depending on local or individual circumstances (Marks et al. 1979; Verhaak, 1986; DeGruy, 1996) and between countries there is also considerable system-related variation (Üstün \& Sartorius, 1995). On the individual level, GPs differ in `available time', ‘personal knowledge of the patient', `skills ' and 'cooperation with other (psychosocial) disciplines '. These factors are positively related to their task perception regarding mental health care (Marks et al. 1979; Verhaak, 1986). The location of the practice in urban or rural areas appeared an important correlate of the position of the GP as an access point to health care provision in general (Boerma et al. 1998) and must be included as an explanatory variable on individual level as well.

On the system-level, wide variations were found in the structure of family practice and the perceived role of GPs in various aspects of curative and preventive care (Boerma et al.

1997; Boerma \& Fleming, 1998). Important differences were found in relation to the referral system and the usual employment status of the GPs. In a referral system, where the GP has a gatekeeping role, he or she is responsible for the first treatment of a circumscribed population of patients (which facilitates the existence of a continued relationship). Self-employed GPs will tend to spend more time on profitable activities instead of `costly ' time-consuming interventions.

Marked differences were also found between the countries in Western and Eastern Europe (Boerma et al. 1998).

These results fit well with a characterization made by Starfield, distinguishing between the individualized care model and the collective care model. In the individualized care model patients are usually registered with the GP, which enables the development of a continued relationship, and the doctor is working in a referral system with a comprehensive task profile (Starfield, 1992). The collective care model, is dominated by the clinic or hospital. The relationship between doctor and patient is usually not personal and health care is not well integrated.

Individual physician responsibility for a patient does not apply (Starfield, 1992). In an international WHOstudy the recognition of mental disorder in primary care was clearly related to characteristics of the individualized care model (Üstün \& Sartorius, 1995).

The explanations that we identified on the individual level and on the system level may be interrelated. For instance, the gatekeeping role of GPs facilitates continuity of care, which we considered important in the recognition of mental disorder, but this may interfere with an urban localization of the practice where there is a larger supply of specialized mental services.

The general question in this paper concerns to what extent the self-perceived position of GPs as the first contacted health professional for patients with psychosocial problems is related to characteristics of the country's health care system, and to characteristics at local and individual level. In particular, we have examined the hypothesis that this position is more comprehensive in health care systems aligned to the individualized care model, as described above.

At the level of the practice and individual GP we evaluate the comprehensiveness of this position in relation to characteristics indicating the GP's available time, knowledge of the patient's situation and professional skills. These are reflected in aspects of workload, practice organization, contacts with social workers, education and training, the record system in place and the location of the practice in urban or rural areas.

\section{METHOD}

This paper is based on data gathered in the European Study of Task Profiles of General Practitioners, conducted in 1993 and 1994, involving 7233 responding GPs in 30 European countries (Boerma et al. 1997). The study included questions relevant to the role of the family doctor as the first contacted health professional for patients with psychosocial problems. This role was assessed in the responses to a set of seven concise case scenarios (see Table 1). Answers were pre-coded on a 4-point scale ranging from 'almost never' to ‘almost always' involved. Questionnaires were presented to GPs in their own language. Translations provided by national coordinators were checked by licensed translators. Recruitment of 
Boerma, W.G.W., Verhaak, P.F.M. The general practitioner as the first contacted health professional by patients with psychosocial problems: a European study. Psychological Medicine: 1999, 29(3), p. $689-696$

physicians and distribution of questionnaires was done by the national representatives ; the sampling frame was the family doctors or GPs and the required procedure was a random sampling. The overall response rate was almost $50 \%$. Response rates

\section{[TABLE 1].}

were higher in countries with salaried GPs than in those with self-employed GPs and also higher in countries in Central and Eastern Europe than in those in the West.Acomparison with available national population parameters showed the existence of some recruitment biases. The gender distribution was available in 22 countries and comparison showed a lower than average participation of female family doctors (in 16 of these countries the deviation was no more than 5\%). Comparison on age, which was possible in 20 countries, showed lower participation rates for the oldest and youngest age groups (in 16 of these countries the difference in average age was no more than 2 years) (Boerma et al. 1997).

\section{Dependent variable}

The dependent variable is the GP's perception of where his or her patients will go for a first professional consultation in the seven cases described in Table 1. The answer was a score on a 4-point scale, varying from '(almost) always the doctor of first contact' to `seldom/never'.

The cases were selected from a list used in the so-called Interface Study (Crombie et al. 1990) and adapted in a consensus procedure with representatives from the participating countries.

Cases have been selected with two aims: first, they should discriminate between GPs on the skills required to deal with the problem and, secondly, task assignment should be ambiguous, cases should not be obviously a task for GPs only, but also possibly assigned to other professionals.

Gender and age of the patients were added to the cases to make them more realistic, and not as an indication of specific skills needed.

This list of problems was checked for skewness in the answers (criterion was $85 \%$ or more positive or negative answers). No items had to be removed. The items appeared to form a scale with a Cronbach alpha reliability coefficient of $0-90$. Individual GP scores were calculated by dividing the sum of the scores per item (ranging from 1-4) by seven. The higher the score, the higher the perceived role. National scores were calculated by aggregation of the individual average scores (Boerma et al. 1997).

\section{Independent variables}

Individualized care, as conceptualized by Starfield, was operationalized in the following two variables: the requirement for patient registration with an individual doctor or a practice (the so called patient list system); and referral role of GPs with respect to control of access to secondary care. Two more relevant characteristics of a country's health care system were examined (Boerma et al. 1997). These were: the (prevailing) employment status of the GPs; and the geographical region of Europe in which the country is located. The position of the countries on these variables at national level was derived from an earlier descriptive study based on literature and information from national experts (Boerma et al. 1993). As indicators of the local perspective (the GP/practice), indicating available time, continuing knowledge of the patient and professional skills, we used the following variables: GP's weekly patient related workload (measured as the average number of patient encounters made on practice premises, plus twice the number of home visits, plus half the number of telephone encounters; this weighing procedure was derived from the GP payment contract in the Netherlands); the establishment of an appointment system for patients ; the estimated average duration of consultations by appointment (as normally booked in the agenda); the usual delay between a request for an appointment and the real encounter for persons with non-acute illness ; the record system in place for the patient's medical data; the existence of regular meetings with social workers; the completion of postgraduate (vocational) training in family practice ; the degree of urbanization of the practice area (inner city, urban, suburban, mixed, rural) ; and, the age and gender of the family doctor. Average scores for the perceived involvement in psychosocial problems were compared for the defining characteristics and the differences were evaluated, using analysis of variance tests.

However, sources of variation in the scope of services of GPs are located at two levels : the local level (GPs and practices) and the national level (health care system). To avoid the drawback of aggregation (loss of information) or disaggregation (over-estimating the effects of the higher level variables) the data were analysed using the hierarchical linear model (Jones, 1993; DiPrete \& Forristal, 1994) with the MLn software (Woodhouse, 1995). Although theoretically three levels can be identified, the country, the practice 
Boerma, W.G.W., Verhaak, P.F.M. The general practitioner as the first contacted health professional by patients with psychosocial problems: a European study. Psychological Medicine: 1999, 29(3), p. 689-696

and the GP, only two levels have been distinguished, because the effects of the practice and the GP cannot be separated here.

\section{RESULTS}

The GP as the first professional contact for psychosocial problems

In the diagram presented in Fig. 1 the average national positions of GPs have been described. Large differences were found between countries.

The GP's self-perceived role as the first professional contact with psychosocial problems is most comprehensive in Denmark, The Netherlands, United Kingdom, Croatia and Ireland and very weak in Turkey, Lithuania, Bulgaria and Estonia.

\section{[FIGURE 1, TABLE 2 AND TABLE 3].}

\section{Variation among health care systems}

The mean scores for the seven psychosocial problems analysed by the variables reflecting the degree of individualized care at national level are given in Table 2. The referral system and the requirement for patient registration (as a subset highly correlated with the referral system), the self-employed status of GPs and practising in Western Europe were associated with higher mean scores than their counterparts.

\section{Variation at local level}

The results of the examination of the practice and doctor characteristics are given in Table 3.

Higher means were reported where an appointment system was established, a comprehensive record system was in place, the family practice workload was high and meetings with social workers occurred at least once a month. Time allocated to patient encounters showed highest scores in the middle of the ranges. With delays for non-acute appointments, lowest means were found in the shortest delay category. Vocationally trained doctors had higher scores than doctors who were not. Higher scores occurred in the age group 41-50 years, and scores were low among doctors less than 30 years of age, though the sample was much smaller. Male GPs reported higher scores than female. There were strong trends in the analysis by location with lowest scores in inner city areas and highest scores in rural areas.

\section{[TABLE 4]}

\section{Two-level analysis}

In a two-level multiple regression analysis, taking into account the nested structure of our data, all mentioned variables, except allocation of consultation time and the delay between appointment and consultation, have been considered.

The two omitted variables only apply to a subset of the GPs. Results are given in Table 4. The intra-class correlation is $0-408$, which means that $41 \%$ of the variance is located at national level and the remaining $59 \%$ at local level. These results emphasize the importance of the role of the GP in a referral system. In countries where GPs do not hold such a position, particularly the former communist countries, the role as the first professional to be contacted by patients with psychosocial problems is perceived to be much lower than in other countries. The requirement of patient registration and the employment status of the GP have no independent effect.

On the local level GPs with a higher workload, those having regular meetings with social workers, those working in rural areas, those routinely keeping medical records, male doctors and those working with an appointment system report a more comprehensive role. In summary, health care system characteristics play a major role but individual and practice characteristics retain an influence.

\section{DISCUSSION}

In general, our results confirm the assumptions made in the Introduction. In the GP's perceived position as the first contact with mental disorder, we found clear differences between physicians in gatekeeping referral systems and those in more liberal health care systems. Clear differences were also found between the Eastern European countries (heirs of a true collective care system) and the Western countries, where varieties of a more individualized health care system prevail. 
Boerma, W.G.W., Verhaak, P.F.M. The general practitioner as the first contacted health professional by patients with psychosocial problems: a European study. Psychological Medicine: 1999, 29(3), p. 689-696

In so far as the GP's employment status represents the possibility of a competing financial interest we found no evidence for the expected relationship. At the level of the individual GP and the practice, GPs who keep medical records routinely (hence are better informed about their patients) more often saw themselves as the first contact for mental disorder. The same was true for GPs meeting with social workers regularly and those vocationally trained; but the explanation here remains a matter of speculation. It may be the cause (improved skills) or the product (need for referral and consultation) of a more comprehensive first contact role. Furthermore, GPs in rural practices more often claim to be the first contact for patients with mental problems compared with GPs who work in urban practices.

Some differences were counter-intuitive: male doctors disclosed higher scores than female, which is in contrast to evidence from other studies that female doctors are better communicators (Roter et al. 1991; Hall et al. 1994; Van den Brink-Muinen, 1996, 1997). Although the seven problems in the questionnaire were not gender specific, the description concerned more male than female patients. Further analysis of our data showed that this may have biased the results, because the only item that does not contribute significantly to the difference between male and female doctors in the multiple regression equation is the only item in which a woman is the subject. Besides, GPs with the highest workload and those who have relatively short patient encounters reported a more comprehensive first contact position than doctors with lower workloads and longer patient consultations.

This seems to be the working style that is usual in many British and Dutch practices.

Despite an interrelation of the variables on health care system level and individual level (e.g. a referral system more or less implies patient lists and is a good condition for comprehensive medical record keeping), effects of most variables at an individual level remained statistically significant after controlling for effects on health system level. Indeed, working in a referral system is of major importance for the GP's perceived first contact position regarding mental disorder, but within each type of health care system, the variables on the individual level keep an independent impact.

The generalizability of our findings also needs to be considered. We did not measure the GP's actual position as the first contact with mental disorder but his/her perception of it. These two concepts are not similar, but we assume that doctors, who perceive themselves as the usual first contact, indeed hold such a position to a higher extent than doctors who perceive this role as small. Thus, perception is assumed to be a good indicator for the actual situation. We also believe that most GPs are well able to make the requested estimation of this position. At some time they will get to know about `first contacts' that occurred elsewhere, either by the patient or by a report from social work or a mental health service. We do not know, however, to which extent this ability to estimate contacts with other services varies systematically between categories of GPs or countries. We recognize that a set of only seven questions cannot represent the totality of psychosocial demand. The items have been selected to depict the interface between family practice and other (categorial) services.

In this way they represent a good perspective of the comprehensiveness of the GP's role. We identified some response bias by age and gender, but since the study was based on such large numbers of responding doctors, we believe the effects of these under-representations are small.

Finally, the implications of our results. If the involvement of GPs as the first professional contact for patients with mental disorders is considered desirable, two approaches seem possible. On the individual level, GPs should be encouraged to cooperate with social workers and mental health care professionals, to keep adequate medical records of their patients and to complete a comprehensive vocational training scheme. With respect to the structure of health care a referral system with gatekeeping GPs should be strongly recommended.

Essential contributions to the European Study on Task Profiles of General Practitioners have been made by the national coordinators. Furthermore, Peter Spreeuwenberg is acknowledged for his role in the analysis of the data and Douglas Fleming for his comments on previous versions of the paper. The study was implemented by funding from the European Union in the framework of the BIOMED1 programme (contract BMH1-CT92-1636).

\section{REFERENCES.}

Bensing, J. M. \& Verhaak, P. F. M. (1994). Psychische problemen in de huisartspraktijk veelvormiger en diffuser dan in de psychiatrie. (Psychological problems in general practice more varied and diffuse than in psychiatry.) Nederlands Tijdschrift voor Geneeskunde 138, 130-135. 
Boerma, W.G.W., Verhaak, P.F.M. The general practitioner as the first contacted health professional by patients with psychosocial problems: a European study. Psychological Medicine: 1999, 29(3), p. 689-696

Boerma, W. G. W., De Jong, F. A. J. M. \& Mulder, P. H. (1993). Health Care and General Practice across Europe. NIVEL/NHG: Utrecht.

Boerma, W. G. W., Van der Zee, J. \& Fleming, D. (1997). Service profiles of general practitioners in Europe. British Journal of General Practitioners 47, 481-486.

Boerma, W. G. W., Groenewegen, P. P. G. \& Van der Zee, J. (1998). General practice in urban and rural Europe; the range of curative services. Social Science and Medicine 47, 445-453.

Boerma, W. G. W. \& Fleming, D. M. (1998). The Role of General Practice in Primary Health Care. WHO Europe, The Stationery Office: London.

Crombie, D. L., Van der Zee, J. \& Backer, P. (1990). The Interface Study. Occasional Paper 48. Royal

College of General Practitioners : London.

DeGruy, F. (1996). Mental health care in the primary care setting. In Primary Care: America's Health in a New Era (ed. M. S.

Donaldson, K. D. Yordy, K. N. Lohr and N. A. Vanselow), pp. 285-311. National Academy Press :

Washington, DC.

DiPrete, D. A. \& Forristal, J. D. (1994). Multilevel models: methods and substance. Annual Review of Sociology 20, 331-357.

Gater, R., De Almeida e Sousa, B., Barrientos, G., Caraveo, J., Chandrashekar, C. R. \& Dhadphale, M. (1991). The pathways to psychiatric care : a cross-cultural study. Psychological Medicine 21, 761-774.

Goldberg, D. \& Huxley, P. (1980). Mental Illness in the Community: the Pathway to Psychiatric Care.

Tavistock: London.

Goldberg, D. \& Huxley, P. (1992). Common Mental Disorders. Routledge: New York.

Hall, J. A., Irish, J. T., Roter, D. L., Ehrlich, C. M. \& Miller, L. H. (1994). Gender in medical encounters: an analysis of physician and patient communication in a primary care setting. Health and Psychology 13 , 384-392.

Jones, K. (1993). Everywhere is Nowhere: Multilevel Perspectives on the Importance of Place. University of Portsmouth: Portsmouth.

Kirmayer, L. J., Robbins, J. M., Dworkind, M. \& Yaffe, M. J. (1993). Somatization and the recognition of depression and anxiety in primary care. American Journal of Psychiatry 150, 734-741.

Kroenke, K., Spitzer, R. L. \& Williams, J. B. W. (1994). Physical symptoms in primary care. Predictors of psychiatric disorders and functional impairment. Archives of Family Medicine 3, 774-779.

Marks, J. N., Goldberg, D. P. \& Hillier, V. F. (1979). Determinants of the ability of general practitioners to detect psychiatric illness. Psychological Medicine 9, 337-353.

Olfson, M. (1991). Primary care patients who refuse specialized mental health services. Archives of Internal Medicine 151, 129-132.

Øiesvold, T., Sandlund, M., Hansson, L., Christiansen, L., Göstas, G., Lindhardt, A., Saarento, O., Sytema, S. \& Zandrén, T. (1998).

Factors associated with referral to psychiatric care by general practitioners compared with self-referrals. Psychological Medicine 28, 427-436.

Regier, D. A., Goldberg, I. D., Burns, B. J., Hankin, J., Hoeper, E. W. \& Nycz, G. R. (1982).

Specialist/generalist division of responsibility for patients with mental disorders. Archives of General Psychiatry 39, 219-224.

Roter, D., Lipkin, S. \& Kortgaard, A. (1991). Sex differences in patients' and physicians' communication during primary care visits. Medical Care 29, 1083-1093.

Schulberg, H. C. (1987). Ambulatory mental health liaison research: a review and preview. General Hospital Psychiatry 9, 126-134.

Schurman, R. A., Kramer, P. D. \& Mitchell, J. B. (1985). The hidden mental Health Network. Archives of General Psychiatry 42, 89-94.

Starfield, B. (1992). Primary Care: Concept, Evaluation and Policy. Oxford University Press : New York.

Üstün, T. B. \& Sartorius, N. (1995). Mental Illness in General Health Care. An International Study. John Wiley \& Sons: Chichester.

Van den Brink-Muinen, A. (1996). Gender, Health and Health Care in General Practice. M.D. thesis. NIVEL, Utrecht.

Van den Brink-Muinen, A. (1997). Women's health care : For whom and why? Social Science and Medicine 44, 1541-1551.

Verhaak, P. F. M. (1986). Variations in the diagnosis of psychosocial disorders : a general practice observation study. Social Science and Medicine 23, 595-604.

Verhaak, P. F. M. (1995a). Mental Disorder in the Community and Primary Care. Avebury: Aldershot.

Verhaak, P. F. M. (1995b). Determinants of the help-seeking process: Goldberg and Huxley's first level and first filter. Psychological Medicine 25, 95-104.

Woodhouse, G. (1995). A Guide for MLn for New Users. University of London, Institute of Education: London. 


\section{TABLES AND FIGURE}

Table 1. Seven psychosocial problems: case scenarios

\section{Anxious man, aged 45}

Physically abused child, aged 13

Couple with relationship problems

Man with suicidal inclinations

Woman, aged 50, with psychosocial problems related to her work

Man, aged 32, with sexual problems

Man, aged 52, with alcohol addiction problems

Table 2. Mean scores for perceived 'first contact' with psychosocial problems by characteristics of the health care system on national level

\begin{tabular}{lccc}
\hline \hline System characteristics & Mean $\dagger$ & (s.D.) & $F$ \\
\hline Referral system & & & \\
$\quad$ GP in referral role $(N=2352)$ & $3 \cdot 14$ & $(0 \cdot 70)$ & $877^{* * *}$ \\
$\quad$ No referral system $(N=4258)$ & $2 \cdot 55$ & $(0 \cdot 82)$ & \\
$\quad$ Patients registered with GP & & & \\
$\quad$ Personal doctor $(N=1850)$ & $3 \cdot 16$ & $(0 \cdot 72)$ & $665^{* * *}$ \\
$\quad$ Patients not listed $(N=4760)$ & $2 \cdot 60$ & $(0 \cdot 82)$ & \\
Employment status of GPs & & & \\
$\quad$ Salaried $(N=3759)$ & $2 \cdot 55$ & $(0 \cdot 87)$ & $628^{* * *}$ \\
$\quad$ Self-employed $(N=2818)$ & $3 \cdot 04$ & $(0 \cdot 68)$ & \\
Central/East $v$. West & & & \\
$\quad$ Central/Eastern Europe $(N=2034)$ & $2 \cdot 21$ & $(0 \cdot 81)$ & $1578^{* * * *}$ \\
$\quad$ West $(N=4576)$ & $3 \cdot 00$ & $(0 \cdot 72)$ & \\
\hline \hline
\end{tabular}

$\dagger$ Range 1-4.

*** $P<0.001$. 
FIG. 1. MEAN AGgREgATE SCORES (RANGE 1-4) PER COUNTRY ON THE GP'S PERCEIVED ROLE AS THE FIRST PROFESSIONAL CONTACT FOR PATIENTS WITH PSYCHOSOCIAL PROBLEMS.

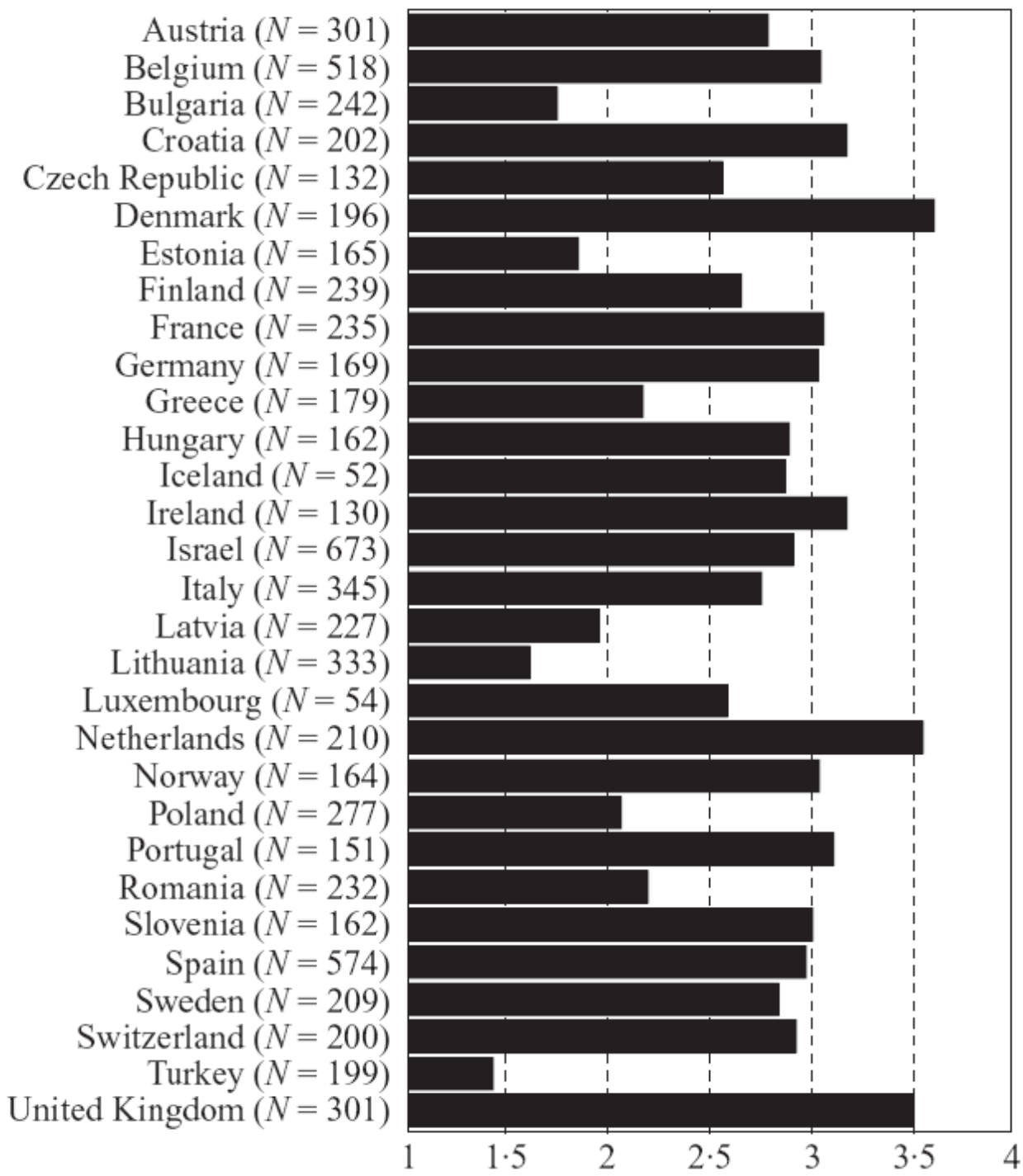


Boerma, W.G.W., Verhaak, P.F.M. The general practitioner as the first contacted health professional by patients with psychosocial problems: a European study. Psychological Medicine: 1999, 29(3), p. $689-696$

Table 3. Mean scores for perceived 'first contact role' with psychosocial problems by variables on local level

\begin{tabular}{|c|c|c|c|}
\hline Practice conditions & Mean $\dagger$ & (S.D.) & $F$ \\
\hline $\begin{array}{l}\text { Appointment system } \\
\quad \text { None or for minority only }(N=3706) \\
\text { For all or majority of patients }(N=2865)\end{array}$ & $\begin{array}{l}2 \cdot 58 \\
3.00\end{array}$ & $\begin{array}{l}(0 \cdot 85) \\
(0 \cdot 75)\end{array}$ & $427 * * *$ \\
\hline $\begin{array}{l}\text { Time usually allocated per patient } \\
\quad \leqslant 5 \min (N=159) \\
6-10 \min (N=1110) \\
11-15 \min (N=1049) \\
>15 \min (N=966)\end{array}$ & $\begin{array}{l}2 \cdot 99 \\
3 \cdot 17 \\
2 \cdot 92 \\
2 \cdot 77\end{array}$ & $\begin{array}{l}(0 \cdot 81) \\
(0 \cdot 74) \\
(0 \cdot 75) \\
(0 \cdot 74)\end{array}$ & $52 * * *$ \\
\hline $\begin{array}{l}\text { Usual waiting time non-acute patients } \\
\text { Same day }(N=2021) \\
\text { Next day }(N=842) \\
\geqslant 2 \text { days }(N=1244)\end{array}$ & $\begin{array}{l}2 \cdot 83 \\
3 \cdot 00 \\
2 \cdot 98\end{array}$ & $\begin{array}{l}(0 \cdot 84) \\
(0 \cdot 73) \\
(0 \cdot 69)\end{array}$ & $21 * * *$ \\
\hline $\begin{array}{l}\text { Records of patient's medical history } \\
\text { None or regular attenders only }(N=1091) \\
\text { For all patients in the practice }(N=5437)\end{array}$ & $\begin{array}{l}2 \cdot 40 \\
2 \cdot 83\end{array}$ & $\begin{array}{l}(0 \cdot 85) \\
(0 \cdot 81)\end{array}$ & $248 * * *$ \\
\hline $\begin{array}{l}\text { Workload patient care } \\
\text { First quartile }(N=1373) \\
\text { Second quartile }(N=1460) \\
\text { Third quartile }(N=1433) \\
\text { Fourth quartile }(N=1529)\end{array}$ & $\begin{array}{l}2 \cdot 52 \\
2 \cdot 72 \\
2 \cdot 92 \\
3 \cdot 02\end{array}$ & $\begin{array}{l}(0 \cdot 81) \\
(0 \cdot 85) \\
(0 \cdot 78) \\
(0 \cdot 72)\end{array}$ & $112 * * *$ \\
\hline $\begin{array}{l}\text { Regular meetings with social work } \\
\text { Seldom/never }(N=1735) \\
<3 \text { monthly }(N=1257) \\
\text { Every } 1-3 \text { months }(N=1348) \\
>\text { Once a month }(N=1286)\end{array}$ & $\begin{array}{l}2 \cdot 66 \\
2 \cdot 82 \\
2 \cdot 92 \\
2 \cdot 99\end{array}$ & $\begin{array}{l}(0 \cdot 86) \\
(0 \cdot 78) \\
(0 \cdot 74) \\
(0 \cdot 76)\end{array}$ & $49 * * *$ \\
\hline $\begin{array}{l}\text { Vocational training } \\
\text { No training }(N=2996) \\
\text { Completed or in training }(N=3512)\end{array}$ & $\begin{array}{l}2 \cdot 62 \\
2 \cdot 89\end{array}$ & $\begin{array}{l}(0 \cdot 88) \\
(0 \cdot 76)\end{array}$ & $177 * * *$ \\
\hline $\begin{array}{l}\text { GPs' age } \\
\quad \leqslant 30(N=295) \\
31-40(N=2482) \\
41-50(N=2497) \\
51-60(N=933) \\
>60(N=372)\end{array}$ & $\begin{array}{l}2 \cdot 14 \\
2 \cdot 70 \\
2 \cdot 90 \\
2 \cdot 74 \\
2 \cdot 72\end{array}$ & $\begin{array}{l}(0 \cdot 89) \\
(0 \cdot 83) \\
(0 \cdot 78) \\
(0 \cdot 82) \\
(0 \cdot 84)\end{array}$ & $64 * * *$ \\
\hline $\begin{array}{l}\text { GPs' gender } \\
\text { Male }(N=4229) \\
\text { Female }(N=2368)\end{array}$ & $\begin{array}{l}2 \cdot 90 \\
2 \cdot 50\end{array}$ & $\begin{array}{l}(0 \cdot 78) \\
(0 \cdot 86)\end{array}$ & $378 * * *$ \\
\hline $\begin{array}{l}\text { Geographical practice location } \\
\text { Urban (inner city) }(N=1482) \\
\text { Urban (small town) }(N=1423) \\
\text { Suburban }(N=748) \\
\text { Mixed urban/rural }(N=1367) \\
\text { Rural }(N=1561)\end{array}$ & $\begin{array}{l}2 \cdot 45 \\
2 \cdot 67 \\
2 \cdot 86 \\
2 \cdot 91 \\
2 \cdot 96\end{array}$ & $\begin{array}{l}(0 \cdot 90) \\
(0 \cdot 84) \\
(0 \cdot 76) \\
(0 \cdot 74) \\
(0 \cdot 77)\end{array}$ & $98 * * *$ \\
\hline
\end{tabular}

$\dagger$ Range 1-4.

*** $P<0.001$.

†. Only applicable to GPs using an appointment system. 
Table 4. Two-level regression analysis on GP'S perceived 'first contact role' with psychosocial problems $(N=4901)$

\begin{tabular}{lrl}
\hline \hline Variables & $\beta$ & $t$ \\
\hline National level & & \\
$\quad$ Referral system (1 = yes) & $0 \cdot 35$ & $4 \cdot 08^{* * *}$ \\
Patients registration (1 = yes) & $0 \cdot 04$ & $0 \cdot 43^{\mathrm{Ns}}$ \\
Employment status (1 = self-employed) & $0 \cdot 14$ & $1 \cdot 94^{\mathrm{Ns}}$ \\
European region (1 = West) & $0 \cdot 21$ & $2 \cdot 59^{* *}$ \\
Local level & & \\
Appointment system (1= yes) & $0 \cdot 04$ & $2 \cdot 54^{* * *}$ \\
Medical records routinely (1 = yes) & $0 \cdot 07$ & $5 \cdot 25^{* * *}$ \\
Workload & $0 \cdot 13$ & $9 \cdot 21^{* * *}$ \\
Meetings with soc. work (1 = regular) & $0 \cdot 10$ & $8 \cdot 31^{* * *}$ \\
Vocationally trained (1 = yes) & $0 \cdot 05$ & $3 \cdot 80^{* * *}$ \\
GP's age & $-0 \cdot 03$ & $2 \cdot 51^{* *}$ \\
GP's gender (1 = female) & $-0 \cdot 05$ & $4 \cdot 04^{* * *}$ \\
Urbanization (1 = rural) & $0 \cdot 08$ & $6 \cdot 84^{* * *}$ \\
\hline \hline
\end{tabular}

** $P<0 \cdot 01 ; * * * P<0 \cdot 001 ;$ NS. 